\title{
The impact of serum vancomycin levels and minimum inhibitory concentrations of methicillin-resistant Staphylococcus aureus on mortality in patients with nosocomial pneumonia
}

\author{
Denise Pires Machado Pharm D PhD, Luciano Z Goldani PhD MD, Rodrigo Minuto Paiva PharmD MSc, \\ Valério Rodrigues Aquino PharmD PhD, Fernanda de-Paris PharmD PhD, Thiago Lisboa PhD MD, \\ Bruno Jung MD, Rodrigo Pires dos Santos PhD MD
}

\begin{abstract}
DP Machado, LZ Goldani, RM Paiva, et al. The impact of serum vancomycin levels and minimum inhibitory concentrations of methicillin-resistant Staphylococcus aureus on mortality in patients with nosocomial pneumonia. Can J Infect Dis Med Microbiol 2013;24(3):e75-e79.
\end{abstract}

BACKGROUND: Vancomycin is the treatment of choice for methicillin-resistant Staphylococcus aureus (MRSA) infections; however, treatment failure is not uncommon, even when the minimum inhibitory concentration (MIC) of the MRSA strain is within the susceptible range for vancomycin.

OBJECTIVE: To describe the relationship between molecular markers such as the mecA and agrII genes, serum vancomycin levels and vancomycin MICs, and the 30-day mortality rate of patients with nosocomial MRSA pneumonia in an intensive care unit (ICU).

METHODS: The present study was a prospective cohort study including all patients with MRSA hospital-acquired pneumonia or ventilator-associated pneumonia who were admitted to the ICU of a tertiary care hospital between June 2009 and December 2011. The MIC for vancomycin was determined using the E-test and broth microdilution methods. Variables analyzed included age, sex, comorbid conditions, serum vancomycin trough concentration, the Acute Physiology and Chronic Health Evaluation II (APACHE) score and the presence of the agrll gene. The primary outcome was mortality at 30 days.

RESULTS: Thirty-six (42.4\%) patients died within 30 days of the index MRSA culture. A multiple regression analysis that included the variables of MIC (determined using the E-test or broth microdilution methods), APACHE II score, serum vancomycin level and the presence of agrII revealed that only the APACHE II score was related to the 30-day mortality rate $(\mathrm{P}=0.03)$. Seven patients $(9.0 \%)$ with isolates exhibiting an $\mathrm{MIC} \geq 1.5 \mu \mathrm{g} / \mathrm{mL}$ according to the E-test method died, and nine patients $(11.6 \%)$ survived $(\mathrm{P}=0.76)$. Of the patients for whom MICs were determined using the broth microdilution method, 11 (14.1\%) patients with MICs of $1.0 \mu \mathrm{g} / \mathrm{mL}$ died, and $16(20.5 \%)$ survived $(\mathrm{P}=0.92)$. The median APACHE II score of survivors was 22.5 , and the median score of nonsurvivors was $25.0(\mathrm{P}=0.03)$. The presence of the agrII gene was not related to the 30 -day mortality rate.

CONCLUSIONS: Patients with severe hospital-acquired pneumonia presented with MRSA isolates with low to intermediate vancomycin MICs in the ICU setting. At the Hospital de Clinicas de Porto Alegre (Porto Alegre, Brazil), the 30-day mortality rate was high, and was similar among patients with severe hospital-acquired pneumonia infected with MRSA isolates that exhibited MICs of $\leq 1.5 \mu \mathrm{g} / \mathrm{mL}$ determined using the E-test method and $\leq 1.0 \mu \mathrm{g} / \mathrm{mL}$ determined using the broth microdilution method in those who achieved optimal serum vancomycin levels. The APACHE II scores which provides an overall estimate of ICU mortality were independently associated with mortality in the present study, regardless of the MICs determined. Molecular markers, such as the agrII gene, were not associated with higher mortality in the present study.

Key Words: Methicillin-resistant Staphylococcus aureus; Nosocomial pneumonia; Vancomycin
Les répercussions des taux de vancomycine sérique et des concentrations minimales inhibitrices de Staphylococcus aureus résistant à la méthicilline sur la mortalité des patients atteints d'une pneumonie d'origine nosocomiale

HISTORIQUE : La vancomycine est le traitement de première intention des infections par le Staphylococcus aureus résistant à la méthicilline (SARM), mais les échecs thérapeutiques ne sont pas rares, même lorsque la concentration minimale inhibitrice (CMI) de la souche de SARM se situe dans la plage susceptible de vancomycine.

OBJECTIF : Décrire le lien entre les marqueurs moléculaires comme les gènes mecA et agrII, le taux de vancomycine sérique et la CMI de vancomycine, et le taux de mortalité au bout de 30 jours des patients atteints d'une pneumonie à SARM d'origine nosocomiale à l'unité de soins intensifs (USI).

MÉTHODOLOGIE : La présente étude prospective de cohorte incluait tous les patients ayant une pneumonie à SARM d'origine nosocomiale ou d'une pneumonie acquise sous ventilation mécanique qui ont été hospitalisés à l'USI d'un hôpital de soins tertiaires entre juin 2009 et décembre 2011. Les chercheurs ont déterminé la CMI de la vancomycine au moyen des méthodes d'E-test et de microdilution en bouillon. Les variables qu'ils ont analysées sont l'âge, le sexe, les états comorbides, la concentration minimale de vancomycine sérique, le score APACHE (évaluation de physiologie aiguë et de maladie chronique II) et la présence du gène agrII. La mortalité au bout de 30 jours était l'issue primaire.

RÉSULTATS : Trente-six patients $(42,4 \%)$ sont décédés dans les 30 jours suivant la culture de référence du SARM. Une analyse de régression multiple qui incluait les variables de la CMI (déterminée au moyen des méthodes d'E-test ou de microdilution en bouillon, le score APACHE II, le taux de vancomycine sérique et la présence du gène $\mathrm{f}$ agrII a révélé que seul le score APACHE II était lié au taux de mortalité au bout de 30 jours $(P=0,03)$. Sept patients $(9,0 \%)$ dont les isolats présentaient une CMI d'au moins $1,5 \mu \mathrm{g} / \mathrm{mL}$ d'après la méthode d'E-test sont décédés, et neuf patients $(11,6 \%)$ ont survécu $(\mathrm{P}=0,76)$. Chez les patients dont la CMI a été déterminée au moyen de la méthode de microdilution en bouillon, 11 (14,1\%) ayant une CMI de 1,0 $\mu \mathrm{g} / \mathrm{mL}$ sont décédés et 16 (20,5\%) ont survécu $(\mathrm{P}=0,92)$. Les survivants avaient un score APACHE II médian de 22,5 , et les non-survivants, de $25,0(\mathrm{P}=0,03)$. La présence du gène agrII n'était pas liée au taux de décès au bout de 30 jours.

CONCLUSIONS : Les patients ayant une grave pneumonie d'origine nosocomiale présentaient des isolats de SARM à la CMI faible à intermédiaire à la vancomycine à l'USI. Au Hospital de Clínicas de Porto Alegre (Porto Alegre, Brésil), le taux de mortalité au bout de 30 jours était élevé, tout comme chez les patients atteints d'une grave pneumonie d'origine nosocomiale infectés par des isolats du SARM dont la CMI était égale ou inférieure à $1,5 \mu \mathrm{g} / \mathrm{mL}$ d'après par la méthode d'E-test (ou égale ou inférieure à $1,0 \mu \mathrm{g} / \mathrm{mL}$ d'après la méthode de microdilution en bouillon) qui ont atteint des taux optimaux de vancomycine sérique. Les scores APACHE II qui procurent une évaluation globale de la mortalité à l'USI s'associaient de manière indépendante avec la mortalité dans la présente étude, quelle que soit la CMI établie. De plus, les marqueurs moléculaires, tels que le gène agrII, n'étaient pas liés à un taux de mortalité plus élevé y.

Section of Infectious Diseases and Infection Control Hospital Committee, Hospital de Clínicas de Porto Alegre, Universidade Federal do Rio

Grande do Sul, Brazil

Correspondence: Dr Luciano Z Goldani, Infectious Diseases Section, Hospital das Clínicas de Porto Alegre, Ramiro Barcelos, 2350, 90035-903,

Porto Alegre, Rio Grande do Sul, Brazil. Telephone 55-51-3359-8452, fax 55-51-3359-8310, e-mail lgoldani@ufrgs.br 
$\mathrm{M}$ ethicillin-resistant Staphylococcus aureus (MRSA) has become a prevalent nosocomial pathogen worldwide and is a frequent cause of serious infections that are associated with significant morbidity and mortality and high costs of medical care $(1,2)$ MRSA is recognized as a significant cause of pneumonia, particularly in intensive care units (ICUs) (3).

MRSA is often resistant to the majority of antimicrobial agents available for clinical use (1) With limited choices for therapy, vancomycin remains the first-line option to treat these infections (4-6). However, vancomycin treatment failure is not uncommon, even when the minimum inhibitory concentration (MIC) is below the susceptibility breakpoint for $S$ aureus $(\leq 2.0 \mu \mathrm{g} / \mathrm{mL})$ defined by the Clinical Laboratory Standards Institute (CLSI). Some authors have suggested that an alternative treatment option should be considered if the vancomycin MIC is $>1.0 \mu \mathrm{g} / \mathrm{mL}(7-10)$. These studies used the E-test method to correlate elevated MICs with undesirable outcomes. However, the CLSI recommends the use of dilution methods to test vancomycin MICs for $S$ aureus. Furthermore, several studies have demonstrated that MICs determined using the E-test method are one- to two-fold higher than the MICs determined using the broth microdilution method (1114). The objective of the present study was to describe the relationship between molecular makers such as the mecA and agrII genes, serum vancomycin levels and vancomycin MICs generated using both the E-test and broth microdilution methods with the 30-day mortality rate among patients with nosocomial MRSA pneumonia in an ICU.

\section{Study design and population}

\section{METHODS}

A prospective cohort study was conducted at the Hospital de Clínicas de Porto Alegre, a 795-bed academic tertiary care hospital located in Porto Alegre in southern Brazil. All patients admitted to the ICU between June 2009 and December 2011 with hospital-acquired pneumonia (HAP) or ventilator-associated pneumonia (VAP) caused by MRSA were included in the present study.

Adult patients ( $\geq 18$ years of age) were included in the study if they met the American Thoracic Society and the Infectious Diseases Society of America definitions for HAP or VAP and had at least one positive MRSA culture isolated from a respiratory site (15). Patients were excluded if they received $\leq 1$ day of MRSA-specific therapy. For patients with multiple MRSA respiratory cultures, the first vancomycin MIC of the index respiratory culture isolate was included in the analysis $(8,9)$.

\section{Study variables and definitions}

The data collected included demographic characteristics, comorbidities and laboratory results. The variables selected for the analysis included age, sex, comorbid conditions and the mean serum vancomycin trough concentration for each patient according to the recommendations by Rybak et al (4) (vancomycin was dosed according to the pharmacokinetic protocol of the institution to attain a trough of $15.0 \mu \mathrm{g} / \mathrm{mL}$ to $20.0 \mu \mathrm{g} / \mathrm{mL}$ ). The Acute Physiology and Chronic Health Evaluation II (APACHE II) score was calculated for all patients on admission to the ICU to assess the severity of the underlying illness. Comorbidities were classified according to the following categories: chronic obstructive pulmonary disease; cardiac disease; gastrointestinal disease; renal disease; diabetes; neurological disease; solid organ transplant; hematological neoplasia; alcoholism; solid neoplasia; corticosteroid use; HIV disease; bone marrow transplant; and other.

Mortality at 30 days was the primary outcome and was defined as death within 30 days of the index MRSA respiratory culture (8).

\section{Laboratory analysis}

The isolates from respiratory samples were identified according to standard techniques. All tracheal aspirate and bronchoalveolar lavage results were based on quantitative cultures (a diagnostic threshold of $10^{5} \mathrm{cfu} / \mathrm{mL}$ for tracheal aspirates and $10^{4} \mathrm{cfu} / \mathrm{mL}$ for bronchoalveolar lavage fluid). Polymicrobial culture results (more than three microorganisms) were excluded from the analysis.
An initial susceptibility test for oxacillin resistance was performed using a $30 \mu \mathrm{g}$ cefoxitin disc in Mueller-Hinton agar, according to CLSI guidelines (16) Individual isolates were stored in Trypticase soy broth (Becton Dickinson, USA) with $20 \%$ glycerol at $-80^{\circ} \mathrm{C}$ until MIC testing was performed. Vancomycin MICs were determined in duplicate according to the reference broth microdilution method, as recommended by the CLSI, using in-house prepared panels. The following dilutions of vancomycin were tested: $16 \mu \mathrm{g} / \mathrm{mL}, 8 \mu \mathrm{g} / \mathrm{mL}, 4 \mu \mathrm{g} / \mathrm{mL}$, $2 \mu \mathrm{g} / \mathrm{mL}, 1 \mu \mathrm{g} / \mathrm{mL}, 0.5 \mu \mathrm{g} / \mathrm{mL}, 0.25 \mu \mathrm{g} / \mathrm{mL}$ and $0.125 \mu \mathrm{g} / \mathrm{mL}$ (17). The E-test procedure was performed on Mueller-Hinton agar with an inoculum density equal to a $0.5 \mathrm{McF}$ arland turbity standard to create a confluent lawn of microbial growth. The cultures were incubated for $24 \mathrm{~h}$ at $35^{\circ} \mathrm{C}$. S aureus (29213, American Type Culture Collection, USA) was used for quality control. The mecA and agrII genes were detected using PCR with specific primers $(18,19)$. Serum levels of vancomycin were measured using a turbidimetric immunoassay (Dimension RxL, Dade Behring, USA).

\section{Statistical analysis}

A descriptive analysis of patient variables was performed. The continuous variables are reported as medians, and the dispersion measurements are reported as interquartile ranges (IQRs). A one-way ANOVA analysis with a two-sided Bonferroni multiple comparisons test was performed to compare the mean differences in MICs determined using the E-test and broth microdilution methods throughout the study period.

A Cox regression analysis was used for the univariate analysis of selected variables; associations were considered to be statistically significant at $\mathrm{P} \leq 0.05$. The multivariate hazard ratios (HR) and $95 \% \mathrm{CIs}$ were calculated using the Cox proportional hazards regression model. The final model included the variables with $\mathrm{P} \leq 0.05$ according to univariate analysis, or variables that were clinically related to the outcome. The survival analysis was based on the Kaplan-Meier method, and the comparisons of the survival curves were made using the logrank test. The data were analyzed using SPSS version 18.0 (IBM Corporation, USA).

\section{RESULTS}

Eighty-five patients were diagnosed with MRSA pneumonia during the study period. The median age of these patients was 63 years (IQR 49 to 75 years $)$ and $64.7 \%(n=55)$ were men. The median APACHE II score was 23 (IQR 17.5 to 9.0). Of these patients, $88.3 \%$ were diagnosed with MRSA VAP; the MRSA was isolated from tracheal aspirates in $81.2 \%(n=69)$ of the patients and from bronchoalveolar lavage fluid in $7.1 \%(n=6)$ of the patients. The remaining patients had HAP diagnosed using sputum samples $(10.6 \% ; n=9)$ or pleural fluid cultures $(1.2 \% ; n=1)$. Five patients $(5.9 \%)$ had MRSA-associated bacteremia. Forty-six $(54.1 \%)$ of the MRSA isolates were positive for the agrII gene, and the presence of the mecA gene was confirmed in all of the isolates. Vancomycin serum levels were available for 70 patients. The median serum vancomycin level was $20.7 \mu \mathrm{g} / \mathrm{mL}(12.0 \mu \mathrm{g} / \mathrm{mL}$ to $29.1 \mu \mathrm{g} / \mathrm{mL}$ ). The clinical and demographic data of the patients are shown in Table 1.

A comparison of vancomycin MICs determined using the E-test and broth microdilution methods is presented in Table 2. Sixtyeight $(80.1 \%)$ of the MICs determined using the E-test method were $\leq 1.0 \mu \mathrm{g} / \mathrm{mL}$. However, all of the MICs determined using the broth microdilution method were $\leq 1.0 \mu \mathrm{g} / \mathrm{mL}(\mathrm{n}=85)$. The mean $( \pm \mathrm{SD})$ MIC determined using the broth microdilution method increased from $0.55 \pm 0.16 \mu \mathrm{g} / \mathrm{mL}$ (June to November 2009 ) to $0.78 \pm 0.26 \mu \mathrm{g} / \mathrm{mL}$ (July to December 2011) ( $\mathrm{P}=0.04)$. The MICs determined using the E-test method did not change during the study period.

Thirty-six $(42.4 \%)$ patients died within 30 days of the index MRSA culture. The median serum vancomycin levels of the survivors and the nonsurvivors were $20.0 \mu \mathrm{g} / \mathrm{mL}$ and $20.9 \mu \mathrm{g} / \mathrm{mL}$, respectively (HR 0.99 [95\% CI 0.97 to 1.03]; P=0.96). Seven patients (9.0\%) with isolates exhibiting an $\mathrm{MIC} \geq 1.5 \mu \mathrm{g} / \mathrm{mL}$ according to the E-test method died, and nine patients (11.6\%) survived (HR 0.87 [95\% CI 0.36 to 
TABLE 1

Clinical and demographic characteristics of patients with MRSA pneumonia $(n=85)$

\begin{tabular}{lc}
\hline Characteristic & $\mathbf{n}(\%)$ \\
\hline Age, years, median (interquartile range) & $63(49-75)$ \\
Male sex & $55(64.7)$ \\
Comorbidities & \\
Chronic obstructive pulmonary disease & $73(85.9)$ \\
Cardiac disease & $46(54.1)$ \\
Gastrointestinal disease & $27(31.8)$ \\
Renal disease & $26(30.6)$ \\
Diabetes & $23(27.1)$ \\
Neurological disease & $22(25.9)$ \\
Solid organ transplant & $16(18.8)$ \\
Hematological neoplasia & $9(10.6)$ \\
Alcoholism & $8(9.4)$ \\
Solid neoplasia & $7(8.2)$ \\
Corticosteroid use & $7(8.2)$ \\
HIV positive & $5(5.9)$ \\
Bone marrow transplant & $1(1.2)$ \\
Other & $50(58.8)$ \\
Serum vancomycin concentration, $\mu \mathrm{gg} / \mathrm{mL}, \mathrm{n}=70$, & $20.7(12.0-29.1)$ \\
median (interquartile range) & \\
Presence of agrll & $46(54.1)$ \\
Associated MRSA bacteremia & $5(5.9)$ \\
APACHE II score, median (interquartile range) & $23(17.5-29.0)$ \\
30-day mortality & $36(42.4)$ \\
\hline Data presented as $n$ (\%) unless otherwise indicated. APACHE Acute Physiology \\
Assessment and Chronic Health Evaluation; MRSA & Methicillin-resistant \\
Staphylococcus aureus & \\
&
\end{tabular}

2.10]; $\mathrm{P}=0.76$ ). Of the patients for whom MICs were determined using the broth microdilution method, 11 (14.1\%) patients with MICs of $1.0 \mu \mathrm{g} / \mathrm{mL}$ died, and 16 (20.5\%) survived (HR 1.03 [95\% CI 0.51 to 2.09]; $\mathrm{P}=0.92)$. The median APACHE II score of survivors was 22.5 (IQR 9.7 to 26.5), and the median score of nonsurvivors was 25.0 (IQR 19.0 to 29.0; HR 1.05 [95\% CI 1.0 to 1.09 ]; $\mathrm{P}=0.03$ ). The presence of the agrII gene was not related to the 30-day mortality rate. These data are presented in Table 3.

A multiple regression analysis that included the variables of MIC (determined using the E-test or broth microdilution methods), APACHE II score, serum vancomycin level and the presence of agrII revealed that only the APACHE II score was related to the 30-day mortality rate, albeit marginally (HR 1.05 [95\% CI 1.0 to 1.1]; $\mathrm{P}=0.03$ ).

The Kaplan-Meier survival curves in Figure 1 present the survival of MRSA patients according to method used to determine the MIC (E-test $[\leq 1.0 \mu \mathrm{g} / \mathrm{mL}$ versus $\geq 1.5 \mu \mathrm{g} / \mathrm{mL}]$ and broth microdilution $[0.5 \mu \mathrm{g} / \mathrm{mL}$ versus $1.0 \mu \mathrm{g} / \mathrm{mL}])$. According to the log-rank test,
TABLE 2

Vancomycin minimum inhibitory concentrations (MICs) determined using the E-test and broth microdilution methods $(n=85)$

\begin{tabular}{lcc}
\hline & \multicolumn{2}{c}{ Isolates, $\mathbf{n}(\%)$} \\
\cline { 2 - 3 } $\boldsymbol{\mu g} / \mathrm{mL}$ & E-test & $\begin{array}{c}\text { Broth } \\
\text { microdilution }\end{array}$ \\
\hline 0.5 & $6(7.1)$ & $56(65.9)$ \\
0.75 & $14(16.5)$ & - \\
1.0 & $48(56.5)$ & $29(34.1)$ \\
1.5 & $16(18.8)$ & - \\
2.0 & $1(1.2)$ & - \\
\hline
\end{tabular}

there were no differences in survival times, regardless of the method used to measure the MIC (E-test, $\mathrm{P}=0.80$; broth microdilution, $\mathrm{P}=0.83$ ).

\section{DISCUSSION}

In the present study, the majority of patients experienced severe disease (according to APACHE II scores) and VAP. The vancomycin MICs determined using the E-test method were one higher than the MICs determined using broth microdilution, consistent with previous findings by other authors. The majority of patients had MICs $\leq 1.0 \mu \mathrm{g} / \mathrm{mL}$ according to both methods. Our analysis found that 30-day mortality was not associated with vancomycin MICs.

The differences in the MICs calculated using the E-test and broth microdilution methods are well established and were demonstrated in the present study including patients with MRSA pneumonia (11-14). We found a low prevalence of high MICs determined using both the E-test and broth microdilution methods. Sader et al (12) analyzed 1800 MRSA strains from bloodstream infections and found that $96.9 \%$ of the isolates exhibited a vancomycin MIC $\leq 1.0 \mu \mathrm{g} / \mathrm{mL}$, measured using the broth microdilution method. However, Parkash et al (11) used the E-test method and determined that $89 \%$ to $98 \%$ of the samples from bloodstream infections exhibited MICs between $1.5 \mu \mathrm{g} / \mathrm{mL}$ and $2.0 \mu \mathrm{g} / \mathrm{mL}$. Haque et al (9) analyzed respiratory samples and found that the majority (72.8\%) of the patients were infected with MRSA that exhibited an MIC $\geq 1.5 \mu \mathrm{g} / \mathrm{mL}$. Additionally, our results appear to demonstrate an increase in the MICs calculated using the broth microdilution method throughout the study period. Sader et al (20) evaluated the MIC creep of isolates collected from nine medical centers in the United States and found increases in MIC creep in three medical centers between 2002 and 2006.

The Infectious Diseases Society of America guideline for the treatment of MRSA infections recommends that for isolates with a vancomycin MIC $\leq 2.0 \mu \mathrm{g} / \mathrm{mL}$ (vancomycin-susceptible infections), the patient's clinical response should define the drug choice; vancomycin should be used for responding patients, and an alternative therapy should be used for nonresponders regardless of the MIC (21). A recent meta-analysis evaluated 22 studies that examined the clinical response

\section{TABLE 3}

Multivariate analysis comparing risk factors between survivors and patients who died within 30 days

\begin{tabular}{|c|c|c|c|c|}
\hline & Survivors & Nonsurvivors & HR & $\mathbf{P}$ \\
\hline \multicolumn{5}{|l|}{ Vancomycin MIC according to E-test } \\
\hline$\geq 1.5 \mu \mathrm{g} / \mathrm{mL}$ & $9(11.6)$ & $7(9.0)$ & $0.87(0.36-2.10)$ & 0.76 \\
\hline $0.5 \mu \mathrm{g} / \mathrm{mL}$ & $26(33.3)$ & $25(32.1)$ & 1 & - \\
\hline $1.0 \mu \mathrm{g} / \mathrm{mL}$ & $16(20.5)$ & $11(14.1)$ & $1.03(0.51-2.09)$ & 0.92 \\
\hline Serum vancomycin concentration, median (IQR) & $20.0(12.0-27.6)$ & $20.9(11.8-33.5)$ & $0.99(0.97-1.03)$ & 0.96 \\
\hline Negative for agrll & $15(19.2)$ & $19(24.4)$ & 1 & \\
\hline Positive for agrll & $27(34.6)$ & $17(21.8)$ & $0.60(0.31-1.17)$ & 0.13 \\
\hline
\end{tabular}

Data presented as n (\%) unless otherwise indicated. APACHE Acute Physiology Assessment and Chronic Health Evaluation; IQR Interquartile range; MIC Minimum inhibitory concentration 


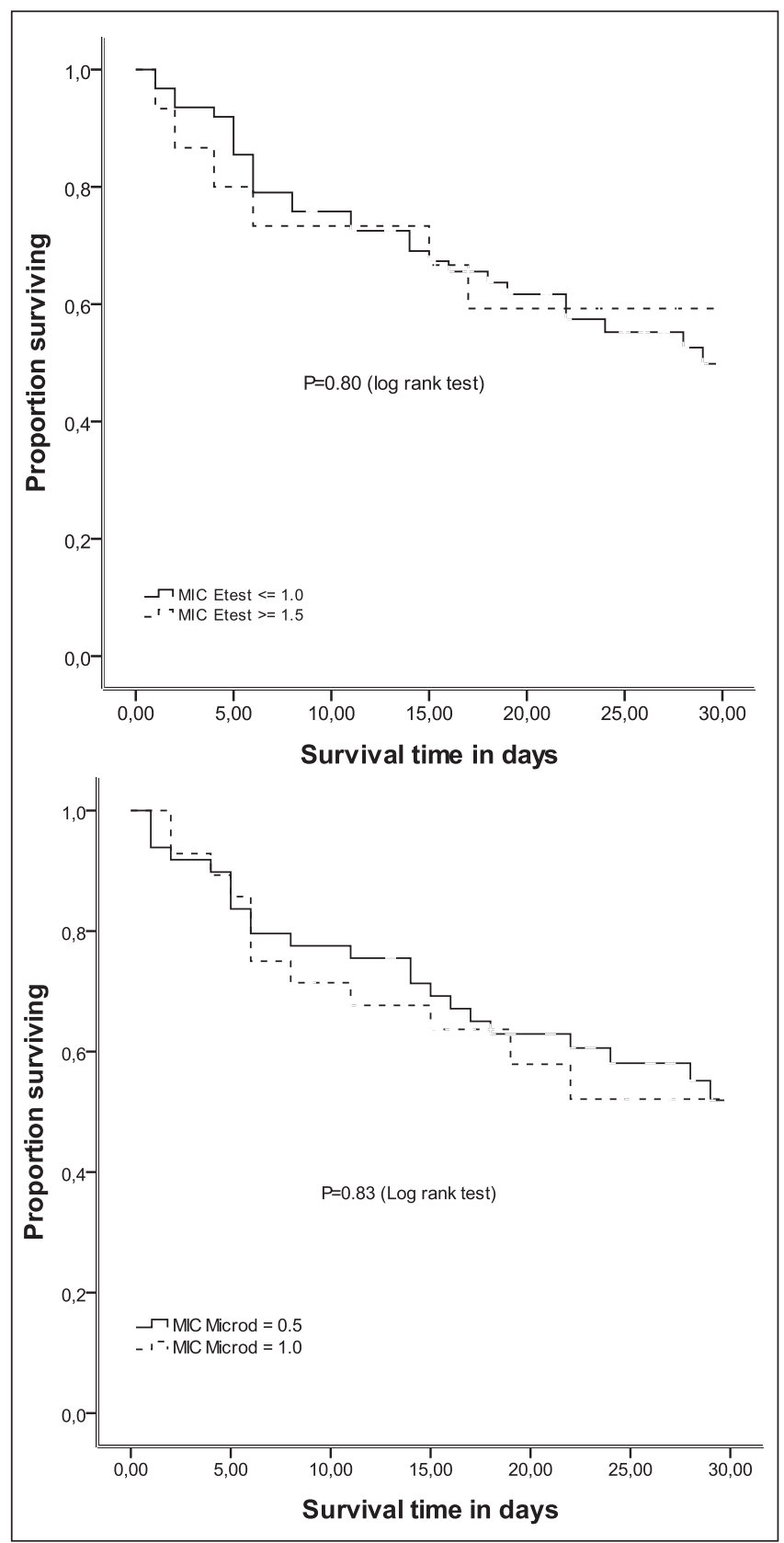

Figure 1) Kaplan-Meier survival estimates of patients with methicillinresistant Staphylococcus aureus respiratory infections according to vancomycin minimum inhibitory concentrations (MICs) determined using the E-test and broth microdilution methods

to vancomycin and the vancomycin MICs of MRSA general infections (22). A high vancomycin MIC was associated with a higher mortality rate in MRSA patients, particularly in patients with bloodstream infections. In this meta-analysis, eight studies that reported MICs determined using the E-test method found that there was no difference in mortality between patients with MRSA infections exhibiting vancomycin MICs of $1.5 \mu \mathrm{g} / \mathrm{mL}$ compared with MICs $\leq 1.0 \mu \mathrm{g} / \mathrm{mL}$. Haque et al (9) evaluated 158 patients with MRSA pneumonia, $72.8 \%$ of whom had infections with a vancomycin $\mathrm{MIC} \geq 1.5 \mu \mathrm{g} / \mathrm{mL}$. The mortality rates were similar between patients with $\mathrm{MIC}<1.5 \mu \mathrm{g} / \mathrm{mL}$ and patients with higher MICs, although a propensity score analysis found an increase in mortality rate after a $1.0 \mu \mathrm{g} / \mathrm{mL}$ increase in MIC determined using the E-test method. However, the authors did not report how many of the 115 patients with an MIC $\geq 1.5 \mu \mathrm{g} / \mathrm{mL}$ actually had an MIC of $2.0 \mu \mathrm{g} / \mathrm{mL}$. In a recent retrospective study involving adults with MRSA nosocomial pneumonia treated with vancomycin, patients infected with MRSA exhibiting high vancomycin MICs $(\geq 1.5 \mu \mathrm{g} / \mathrm{mL})$, determined using the E-test method, demonstrated a slower clinical response and a higher relapse rate than patients infected with isolates exhibiting low vancomycin MICs (23). In our study, $18.8 \%$ of the patients had MRSA isolates exhibiting MICs of $1.5 \mu \mathrm{g} / \mathrm{mL}$ according to the E-test method, and we did not observe higher mortality in these patients when treated with vancomycin compared with patients who had MRSA isolates exhibiting low MICs. Unfortunately, there were no patients with MRSA isolates exhibiting high vancomycin MICs $(\geq 2.0 \mu \mathrm{g} / \mathrm{mL})$ in the present study to compare mortality rates of these patients with patients infected with MRSA isolates exhibiting intermediate and low vancomycin MICs.

The APACHE II score takes into consideration clinical and laboratory variables associated with both acute and chronic diseases, and provides an estimate of ICU mortality. In our study, the median APACHE II score was 23.0, which may explain the high 30-day mortality rates (42\%). Furthermore, the APACHE II scores were independently associated with mortality in our study, regardless of the MICs determined using either the E-test or broth microdilution methods. Vancomycin concentrations were measured in $82 \%$ of patients. The attainment of target vancomycin concentrations was not significantly different between survivors and patients who died $(20.0 \mu \mathrm{g} / \mathrm{mL}$ and $21.0 \mu \mathrm{g} / \mathrm{mL}$, respectively). According to Rybak et al (4), the pharmacodynamic parameter that best predicts vancomycin activity is the ratio of the area under the curve (AUC) to the MIC, with a ratio $\geq 400$ considered to be optimal. Considering the vancomycin trough levels and the MIC, an optimal vancomycin exposure (AUC/MIC $\geq 400$ ) was likely achieved for the majority of our patients.

The accessory gene regulator (Agr) is a quorum-sensing regulator in $S$ aureus that is responsible for biofilm production and the expression of adherence and virulence factors. Some studies have found that MRSA isolates with an agrII polymorphism may influence the clinical efficacy of vancomycin (19-25). The presence of the agrII gene was not associated with higher MICs in our study (data not shown). We found that 46 (54.1\%) of MRSA isolates were positive for the agrII gene. Consistent with results by Moise-Broder et al (19), the presence of agrII was not associated with 30-day mortality in the present study. In a study by Schweizer et al (25), the authors found that $22 \%$ of patients with MRSA had Agr dysfunction, and that the presence of this dysfunction was associated with increased mortality. Mutations that cause Agr dysfunction are associated with changes in the expression of virulence factors. The function of Agr can be examined using the delta hemolysin assay.

Several points must be considered when analyzing our data. We were not able to control for other mortality risk factors in our sample. For example, drug therapy details, such as the time of antibiotic initiation and adjuvant therapies that could interfere with patient mortality, were not controlled for and concomitant respiratory infections were not investigated.

\section{SUMMARY}

Patients with severe HAP presented with MRSA isolates with low to intermediate vancomycin MICs in the ICU setting. In our institution, the 30-day mortality rate was high, and was similar among patients with severe HAP infected with MRSA isolates that exhibited MICs of $\leq 1.5 \mu \mathrm{g} / \mathrm{mL}$ determined using the E-test method and $\leq 1.0 \mu \mathrm{g} / \mathrm{mL}$ determined using the broth microdilution method in those who acheived optimal serum vancomycin levels. The APACHE II scores which provides an overall estimate of ICU mortality were independently associated with mortality in our study, regardless of the MICs determined. Molecular markers, such as the agrII gene, were not associated with higher mortality in our study. There is a need for novel antibiotics to treat MRSA infections and decrease overall mortality of critically ill patients in the ICU setting.

ACKNOWLEDGEMENTS: The present study was supported, in part, by the National Council of Technological and Scientific Development, Brazil $(\mathrm{CNPq})$. 


\section{REFERENCES}

1. Gales AC, Sader HS, Ribeiro J, Zocolli C, Barth A, Pignatari AC. Antimicrobial susceptibility of gram-positive bacteria isolated in Brazilian hospitals participating in the SENTRY program (20052008). Braz J Infect Dis 2009;13:90-8.

2. Howden BP, Davies JK, Johnson PDR, Stinear TP, Grayson L. Reduced vancomycin susceptibility in Staphylococcus aureus, including vancomycin-intermediate and heterogeneous vancomycin-intermediate strains: Resistance mechanisms, laboratory detection, and clinical implications.

Clin Microbiol Rev 2010:23:99-139.

3. Tacconelli E, De Angelis G. Pneumonia due to methicillin-resistant Staphylococcus aureus: Clinical features, diagnosis and management. Curr Opin Pulm Med 2009;15:218-22.

4. Rybak M, Lomaestro B, Rotschafer JC, et al. Therapeutic monitoring of vancomycin in adult patients: A consensus review of the American Society of Health-System Pharmacists, the Infectious Diseases Society of America, and the Society of Infectious Diseases Pharmacists. Am J Health Syst Pharm 2009;66:82-98.

5. Giuliano C, Haase KK, Hall R. Use of vancomycin pharmacokinetic-pharmacodynamic properties in the treatment of MRSA infections. Expert Rev Anti Infect Ther 2010;8:95-106.

6. Patel N, Pai MP, Rodvold KA, Lomaestro B, Drusano GL, Lodise TP. Vancomycin: We can't get there from here. Clin Infect Dis 2011;52:969-974.

7. Soriano A, Marco F, Martinez JÁ, et al. Influence of vancomycin minimum inhibitory concentration on the treatment of methicillinresistant Staphylococcus aureus bacteremia. Clin Infect Dis 2008;46:193-200.

8. Lodise TP, Graves J, Evans A, et al. Relationship between vancomycin MIC and failure among patients with methicillinresistant Staphylococcus aureus bacteremia treated with vancimycin. Antimicrob Agents Chemother 2008;52:3315-20.

9. Haque N, Zuniga LC, Peyrani P, et al. Relationship of vancomycin minimum inhibitory concentration to mortality in patients with methicillin-resistant Staphylococcus aureus hospital-acquired, ventilator-associated, or health-care-associated pneumonia. Chest 2010;138:1356-62.

10. Moore CL, Osaki-Kiyan P, Haque NZ, Perri MB, Donabedian S, Zervos MJ. Daptomycin versus vancomycin for bloodstream infections due to methicillin-resistant Staphylococcus aureus with a high vancomycin minimum inhibitory concentration: A case-control study. Clin Infect Dis 2012;54:51-8.

11. Prakash V, Lewis JS, Jorgensen JH. Vancomycin MICs for methicillin-resistant Staphylococcus aureus isolates differ based upon the susceptibility test method used. Antimicrobial Agents Chemother 2008;52:4528.

12. Sader HS, Rhomberg PR, Jones RN. Nine-hospital study comparing broth microdilution and Etest method results for vancomycin and daptomycin against methicillin-resistant Staphylococcus aureus. Antimicrobial Agents Chemother 2009;53:3162-5.
13. Swenson JM, Anderson KF, Lonsway DR, et al. Accuracy of commercial and reference susceptibility testing methods for detecting vancomycin-intermediate Staphylococcus aureus. J Clin Microbiol 2009;47:2013-7.

14. Machado DP, Nagel F, Aquino VR, et al. Vancomycin minimal inhibitory concentration from broth microdilution and Etest in respiratory tract samples of patients with ventilation-associated pneumonia. J Hosp Infect 2010;76:182-4.

15. American Thoracic Society, Infectious Diseases Society of America. Guidelines for the management of adults with hospital-acquired, ventilator-associated, and healthcare-associated pneumonia. Am J Respir Crit Care Med 2005;171:388-416.

16. Clinical and Laboratory Standards Institute. Performance standards for antimicrobial susceptibility testing. CLSI document M100-S19. Wayne: Clinical and Laboratory Standards Institute 2009.

17. Clinical and Laboratory Standards Institute. Methods for dilution antimicrobial susceptibility tests for bacteria that grow aerobically; approved standard, 8th edn. CLSI document M7-A8. Wayne: Clinical and Laboratory Standards Institute, 2008.

18. Vannuffel P, Gigi J, Ezzedine H, et al. Specific detection of methicillin-resistant Staphylococcus species by multiplex PCR. J Clin Microbiol 1995;33:2864-2867.

19. Moise-Broder PA, Sakoulas G, Eliopoulos GM, Schentag JJ, Forrest A, Moellering RC Jr. Accessory gene regulator group II polymorphism in methicillin-resistant Staphylococcus aureus is predictive of failure of vancomycin therapy. Clin Infect Dis 2004;38:1700-5.

20. Sader HS, Fey PD, Fish DN, et al. Evaluation of vancomycin and daptomycin potency trends (MIC creep) against methicillinresistant Staphylococcus aureus isolates collected in nine U.S. medical centers from 2002 to 2006. Antimicrob Agents Chemother 2009;53:4127-32.

21. Liu C, Bayer A, Cosgrove SE, et al. Clinical practice guidelines by the Infectious Diseases Society of America for the treatment of methicillin-resistant Staphylococcus aureus infections in adults and children. Clin Infect Dis 2011;52:285-92.

22. van Hall SJ, Lodise TP, Paterson DL. The clinical significance of vancomycin minimum inhibitory concentration in Staphylococcus aureus infections: A systematic review and meta-analysis. Clin Infect Dis 2012;54:755-71.

23. Choi EY, Huh JW, Lim CM, et al. Relationship between the MIC of vancomycin and clinical outcome in patients with MRSA nosocomial pneumonia. Intensive Care Med 2011;37:639-47.

24. Sakoulas G, Eliopoulos GM, Moellering RC Jr, et al. Staphylococcus aureus accessory gene regulator (agr) group II: Is there a relationship to the development of intermediate-level glycopeptides resistance? J Infect Dis 2003;187:929-38.

25. Schweizer ML, Furano JP, Sakoulas G, et al. Increased mortality with accessory gene regulator (agr) dysfunction in Staphylococcus aureus among bacteremic patients. Antimicrob Agents Chemother 2011;55:1082-7. 


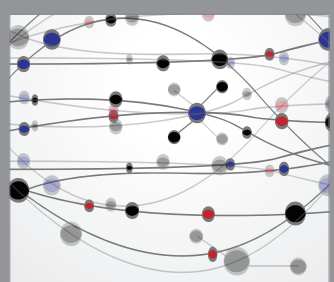

The Scientific World Journal
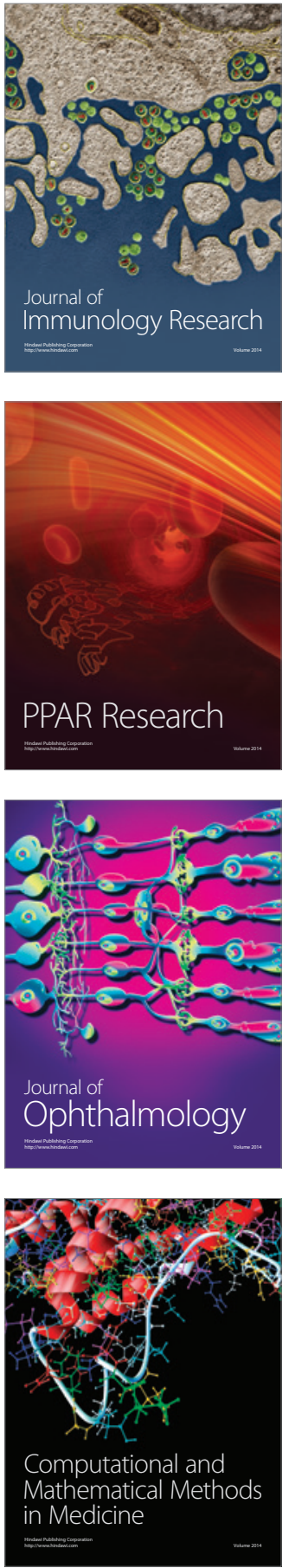

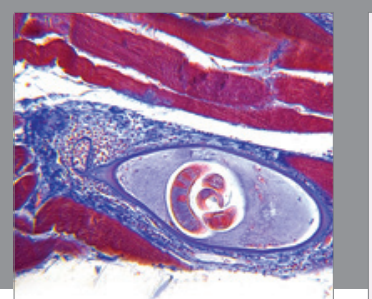

Gastroenterology Research and Practice

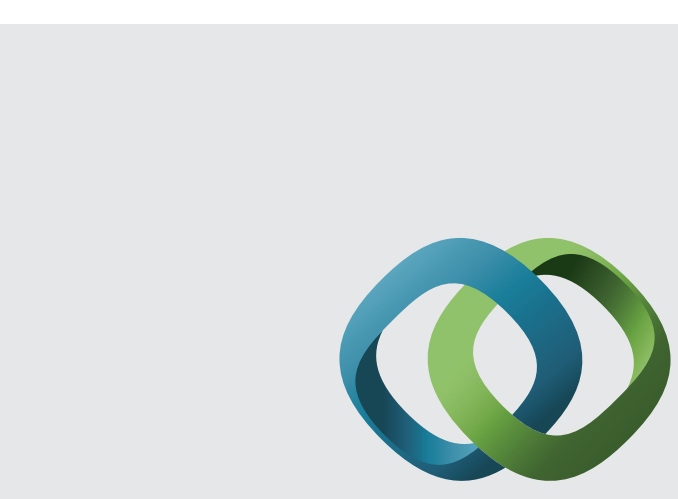

\section{Hindawi}

Submit your manuscripts at

http://www.hindawi.com
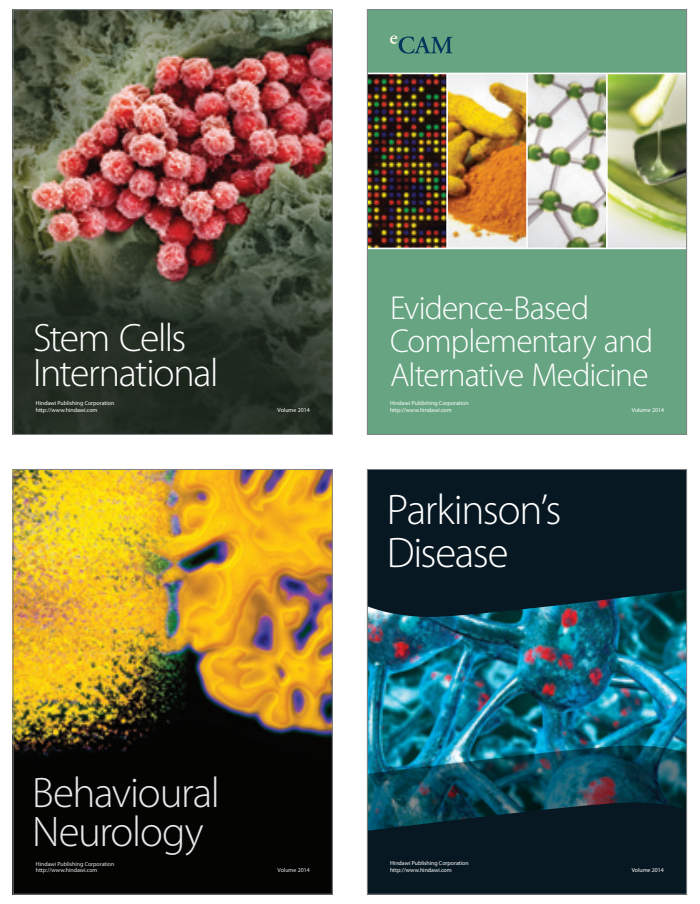
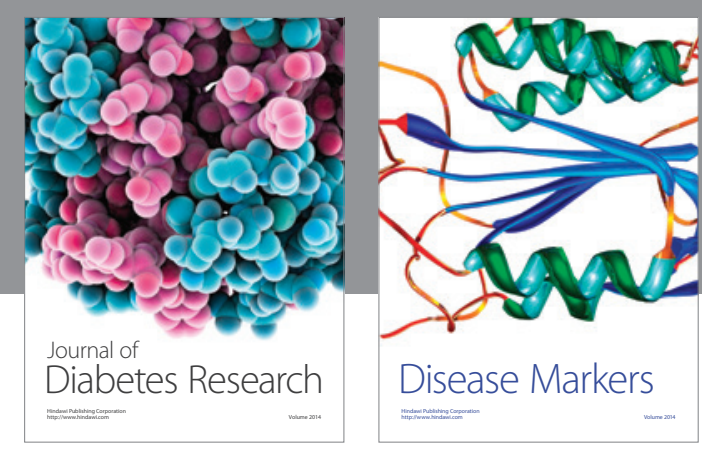

Disease Markers
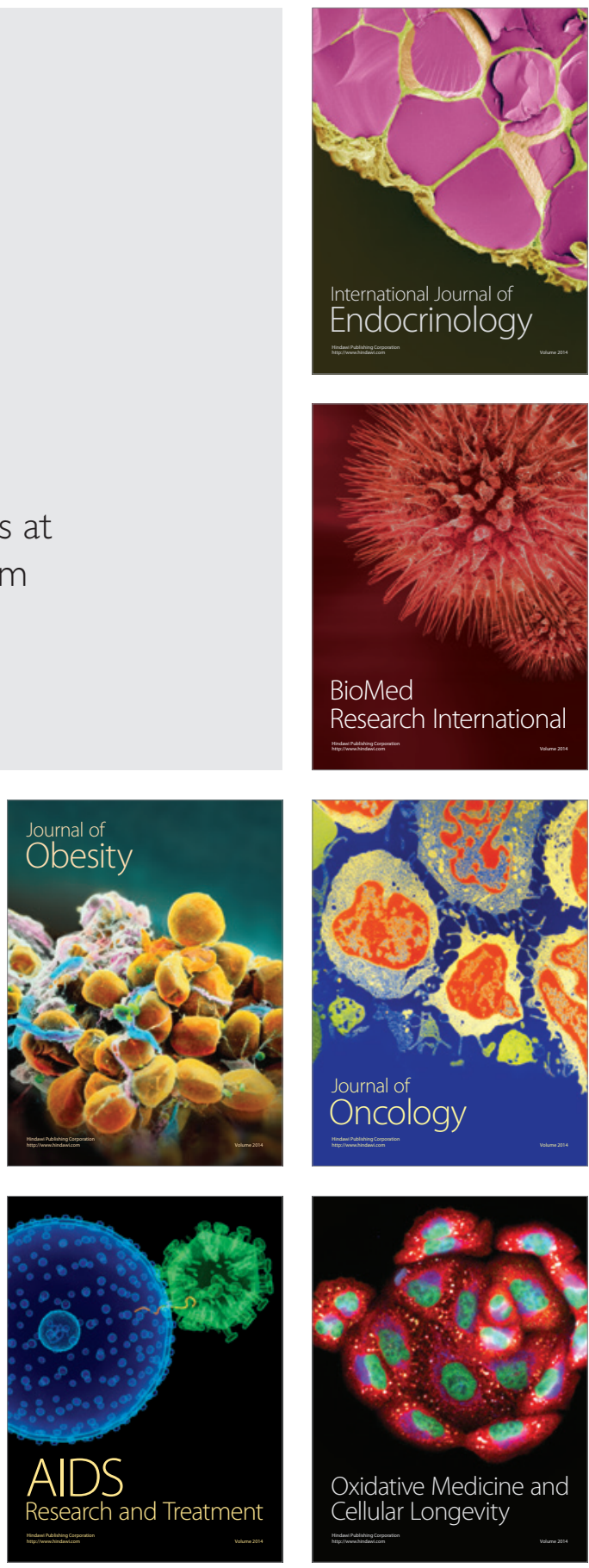